\title{
Uma proposta para o ensino de geografia inspirada em jogos RPG
}

\author{
A proposal for teaching RPG-inspired geography \\ Una propuesta de enseñanza de la geografía inspirada en los RPG
}

Recebido: 20/04/2021 | Revisado: 27/04/2021 | Aceito: 14/05/2021 | Publicado: 01/06/2021

\author{
Sara Pimenta Lima \\ ORCID: https://orcid.org/0000-0002-5118-7958 \\ Secretaria de Estado de Educação do Paraná, Brasil \\ E-mail: sarapmnt@gmail.com \\ Diego Fogaça Carvalho \\ ORCID: https://orcid.org/0000-0002-4984-6344 \\ Universidade Pitágoras Unopar, Brasil \\ Universidade Anhanguera Uniderp, Brasil \\ E-mail: diegofocarva@gmail.com \\ Maria Gracilene de Carvalho Pinheiro \\ ORCID: https://orcid.org/0000-0003-4240-5041 \\ Universidade Pitágoras Unopar, Brasil \\ E-mail: gracilenepinheiro@gmail.com \\ Marcelo Augusto Rocha \\ ORCID: https://orcid.org/0000-0002-9769-0487 \\ Universidade Federal da Integração Latino-Americana, Brasil \\ E-mail: marcellusaugustus@yahoo.com.br \\ Fátima Aparecida da Silva Dias \\ ORCID: https://orcid.org/0000-0002-7371-4579 \\ Universidade Pitágoras Unopar, Brasil \\ Universidade Anhanguera de São Paulo, Brasil \\ E-mail: fatimadias.consultoria@gmail.com \\ Wilian Biserra Chagas \\ ORCID: https://orcid.org/0000-0002-8601-0095 \\ Universidade Anhanguera Uniderp, Brasil \\ E-mail: wilianchagas50@gmail.com \\ Wallace Ferreira Junqueira \\ ORCID: https://orcid.org/0000-0002-8603-8450 \\ Universidade Anhanguera Uniderp, Brasil \\ E-mail: wallace.junqueira@hotmail.com
}

\section{Resumo}

Neste artigo, tem-se por objetivo apresentar uma proposta de ensino para a Geografia Física que assume as simulações advindas das tecnologias digitais como meio para ofertar aos alunos experiências próximas ao trabalho de campo, realizado fora do ambiente escolar. A proposta se estrutura em três teorias que se articulam com o objetivo de configurar um ambiente de aprendizagem, a saber: sequências didáticas, as trajetórias hipotéticas de aprendizagem e o RPG pedagógico. Após apresentação dos conceitos teóricos, analisa-se os diálogos fíctícios elaborados evidenciando como as teorias são articuladas, elucidando a conduta esperada do professor e do aluno para a proposta.

Palavras-chave: Ensino; Tecnologias digitais da informação e comunicação; RPG; Sequência didática; Trajetórias hipotéticas de aprendizagem.

\begin{abstract}
In this article, we have the objective to present an educational proposal for Physical Geography that takes the resulting simulations of digital technologies as a means to offer to students next experiments to field work, done outside the school environment. The proposal is structured in three theories that are articulated with the objective of configuring a learning environment, namely: didactic sequences, hypothetical learning trajectories and pedagogical RPG. After presenting the theoretical concepts, the fictitious dialogues elaborated are analyzed, showing how the theories are articulated, elucidating the conduct of the teacher and the conduct of the student expected for the proposal.

Keywords: Teaching; Digital information and communication technologies; RPG; Didactic sequence; Hypothetical learning trajectories.

\section{Resumen}

En este artículo, el objetivo es presentar una propuesta de enseñanza de Geografía física que asume las simulaciones procedentes de las tecnologías digitales como un medio para ofrecer a los estudiantes las experiencias cercanas a los trabajos de campo, realizados fuera del entorno escolar. La propuesta se estructura en tres teorías que se articulan con el objetivo de configurar un entorno de aprendizaje, a saber: secuencias didácticas, trayectorias hipotéticas de
\end{abstract}


aprendizaje y RPG pedagógico. Luego de presentar los conceptos teóricos, se analizan los diálogos ficticios elaborados, mostrando cómo se articulan las teorías, dilucidando la conducta del docente y la conducta del alumno esperada para la propuesta.

Palabras clave: Ensenãnza; Tecnologías de la información y la comunicación digitales; RPG; Secuencia didáctica; Trayectorias hipotéticas de aprendizaje.

\section{Introdução}

A motivação para a escrita deste artigo versa a inquietude do professor de Geografia em articular os conteúdos de maneira dinâmica, a fim de incentivar nos alunos a curiosidade e a importância da aprendizagem dessa área do conhecimento. Nosso objetivo foi de apresentar uma proposta para o ensino da Geografia Física que assume as simulações advindas das tecnologias digitais como meio para ofertar aos alunos experiências próximas ao trabalho de campo, realizado fora do ambiente escolar.

Elaboramos uma Trajetória Hipotética de Aprendizagem, utilizando conceitos da Geografia Física, coerentes com o $6^{\circ}$ ano do Ensino Fundamental. Todo enredo se deu em um contexto de aprendizagem que advém de uma articulação conceitual entre três teorias, que são: sequências didáticas, a Trajetória Hipotética de Aprendizagem e os Jogos de Role Playing Game (RPG) pedagógicos.

Cabe esclarecer que consideramos, nesta investigação, o conceito de trabalho de campo como a integração entre teoria e prática, como defendida por Compiani (1991, p. 13-14):

[...] o campo é essencial para o entendimento dos princípios e métodos [...], são fundamentais para compreendermos as possibilidades didáticas das atividades de campo [...]. [...] O campo pode ser gerador de problemas, isto é, uma ótima situação de ensino problematizadora [...].

Compiani (1991, p.22) ressalta que o uso do trabalho de campo gera afetividade, motivação na aprendizagem e que

[...] trabalhos de campo orientados aumentam a habilidade de compreensão, aplicação, análise e síntese dos alunos, porque ocorre uma maior interação entre afetividade, motivação e aspectos cognitivos dos estudantes para a aprendizagem.

É de extrema importância ponderar, de acordo com Nascimento (2020), que a inovação no ensino de geografia é importante e há uma série de recursos disponíveis. Todavia, necessita de um direcionamento, diretriz ou base para que as mudanças provocadas pela inserção das tecnologias sejam efetivas. Nesse sentido, neste artigo apresentamos uma forma de promover a inserção das tecnologias de forma gradual no ensino da geografia no âmbito da Educação Básica.

Apresentamos, na seção dois, as tecnologias digitais e o papel que esses recursos podem assumir nos processos de ensino e de aprendizagem da Geografia. Na terceira seção, são definidos os aspectos metodológicos da pesquisa, em que se constrói, fundamentando-se em pesquisa especulativa, um contexto para a proposta, advinda da articulação entre Zabala (1998), Amaral (2008) Simon (1995) e Rossetto (2016). Na seção quatro, apresentamos uma análise dos diálogos hipotéticos elaboradas na simulação de uma Trilha na Floresta, em que se pode evidenciar a articulação teórica construída na seção anterior. Finalizamos o artigo tecendo algumas considerações finais.

\section{Tecnologias no Ensino de Geografia}

Nesta seção são apresentados alguns conceitos e ponderações sobre o uso das tecnologias digitais nos processos de ensino e de aprendizagem da Geografia Física. Nossa interrogativa refere-se a criar um meio alternativo, um mundo virtual, pautado em simulações, para que os alunos possam vivenciar experiências próximas ao trabalho de campo por meio da utilização das tecnologias digitais. Para tal, nos embasamos em leituras que nos possibilitaram elaborar esse contexto. 
De acordo com o Conselho Nacional de Educação, as tecnologias referem-se a uma "transformação da ciência em força produtiva ou mediação de conhecimento científico e a produção, marcada, desde sua origem pelas relações sociais que levaram a ser produzida" (Brasil, 2012, p. 2). As relações sociais permeiam os conteúdos da disciplina de Geografia, daí sua significação à nossa pesquisa.

A sociedade, de maneira geral, e o ambiente escolar, em particular, tem convivido, nas últimas décadas, com as Tecnologia da Informação e Comunicação (TIC) por meio das mais variadas ferramentas, como: retroprojetor, celular, TV, Pendrive, rádios. Atualmente, na chamada era da informação, a escola pode contar com as Tecnologias Digitais da Informação e Comunicação (TDIC), referem-se a recursos pedagógicos que o mundo digital tem oferecido ao professor para auxiliar na abordagem dos conteúdos em sala de aula.

Pesquisas realizadas em diferentes países identificaram um crescimento progressivo nos processos de ensino e de aprendizagem em virtude do uso constante e pedagógico das TDIC em seu cotidiano escolar. (Unesco, 2015). Afirmam que a tecnologia, no ambiente escolar, pode facilitar a aprendizagem efetiva e qualitativa, de modo a " [...] oferecer aos professores as habilidades tecnológicas adequadas para lidar com TIC e redes sociais, bem como habilidades de alfabetização midiática e pensamento crítico" (Unesco, 2016, p.10-26).

Especificadamente, em relação à comunicação de explicações em Geociências, Toledo, Takayama \& Bourotte (2014) discutem a utilização de animações no ensino de Geologia e apontam o potencial dos recursos computacionais para simulações e animações, afirmam que essas ferramentas apresentam potencialidades para o processo de ensino e aprendizagem e o uso da imagem é fundamental na comunicação, não se limitando aos textos verbais, pois a linguagem verbal não é suficiente para dar conta da complexidade das representações e explicações dessa área do conhecimento.

Dois pontos principais podem ser observados até aqui: as TDIC se apresentam como recursos em potencial para o processo de ensino e aprendizagem e a geografia, enquanto disciplina escolar, possibilita a utilização desses recursos no processo de ensino e aprendizagem, facilitando a comunicação de seus conteúdos. Todavia, cabe destacar o papel do professor na inserção das TDIC em sala de aula e a mobilização de conhecimentos específicos sobre a utilização desses recursos em sala de aula.

Assim, muitos estudos têm sido realizados no sentido de discutir o conhecimento tecnológico como componente das competências docentes, sobretudo, em razão das possibilidades didático-pedagógicas que envolvem o uso da tecnologia em sala de aula (Rocha, 2018). Discute-se, por exemplo, o Conhecimento Tecnológico do Conteúdo (Technological Content Knowledge - TCK), cujo domínio refere-se à habilidade de fazer uso e aliar os instrumentos tecnológicos adequados ao ensino de determinada área de formação, promovendo alternativas pedagógicas para a promoção do ensino e da aprendizagem (Rocha, 2018).

Em se tratando do ensino de Geografia, Rocha (2018), afirma que um dos principais desafios desse ensino, na contemporaneidade, é incorporar as TDIC ao cotidiano das aulas e na abordagem do conteúdo. Isso motivou esse pesquisador a desenvolver uma investigação com professores, em que ele os questionou sobre quais conteúdos geográficos são mais indicados para se trabalhar por meio das TDIC.

Os resultados dessa investigação apontaram os conteúdos próximos das Ciências Naturais e da Geografia Física como os mais indicados para se trabalhar por meio de tecnologia em sala de aula. Ao finalizar, o mesmo autor argumentou que, para se conseguir o entendimento sobre o Conhecimento Tecnológico do Conteúdo e de outros conhecimentos que integram o trabalho docente, demanda tempo, dedicação, disciplina e experiência prática em sala de aula.

Essas são algumas reflexões que justificam o objetivo do presente estudo. Compreendemos que os conteúdos da Geografia, em especial a geografia física, podem ser abordados via TDIC, de modo que as simulações do ambiente natural venham a oportunizar experiências próxima ao trabalho de campo. Na próxima seção, procuramos articular os conceitos teóricos 
que utilizamos para compor o contexto em que o jogo de RPG se configurou e apresentamos, também, considerações teóricas sobre o método de pesquisa utilizado nessa articulção.

\section{Construindo um Contexto para a Atividade: Considerações Metodológicas}

Para a composição deste cenário, do ponto de vista metodológico, encontramos na pesquisa especulativa inspirações. Pedrochi-Junior (2018), Rossetto (2021) e Sachs, Baião \& Carvalho (2021) referem-se a exemplos da utilização desse método de pesquisa qualitativa que se centra nos estudos de cunho teórico. Segundo Van Der Maren (1996), tem-se por objetivo a elaboração de declarações teóricas, proveniente de outras declarações.

Martineau, Simard e Gauthier (2001), destacam que os procedimentos metodológicos da pesquisa especulativa se resumem a três pontos: interpretação, argumentação e o recontar. No processo da interpretação, o pesquisador realiza uma leitura hermenêutica dos textos, elabora reflexões e, por fim, interpreta o corpus. Na sequência, o pesquisador deve escrever um texto original, construído por argumentações que advém de suas interpretações. Ao finalizar, no processo do recontar, o pesquisador dialoga com a literatura, produz um problema sem precedentes e propõe uma análise inédita sobre o fenômeno investigado.

Fundamentados nessa perspectiva, o contexto do nosso estudo tomou como base o conceito de Sequência Didática de acordo com Zabala (1998). Para esse autor, uma Sequência Didática é formada por "um conjunto de atividades ordenadas, estruturadas e articuladas para a realização de certos objetivos educacionais, que têm um princípio e um fim conhecidos tanto pelos professores como pelos alunos" (Zabala, 1998, p.18). A necessidade de o professor elaborar uma Sequência Didática é para que se possibilite caminhar de forma segura e previsível durante os processos de ensino e de aprendizagem.

Para embasar esta proposta de ensino, optamos pelo modelo Unidade 4, principalmente pela maneira que o protagonismo discente e docente é configurado. Interpretamos que o autor apresenta nessa sequência a necessidade de se estabelecer um equilíbrio entre o que há de mais clássico na pedagogia, bem como o que há de mais progressista, enfatizando que a prática docente não deve se situar nos extremos, mas procurar um termo intermediário, em que esses componentes possam se articular com o intuito de atingir o objetivo principal: a aprendizagem do aluno.

[...] é uma construção pessoal que cada menino e cada menina realiza graças à ajuda que recebem de outras pessoas. Esta construção, através da qual podem atribuir significado a um determinado objeto de ensino implica a contribuição por parte da pessoa que aprende, de seu interesse e disponibilidade, de seus conhecimentos prévios e de sua experiência. (Zabala, 1998, p. 63).

Aliado a esse constructo, para direcionar a condução do professor frente à prática pedagógica, alinhamos à Trajetória Hipotética de Aprendizagem (THA) de Simon (1995). Esse autor tece suas primeiras considerações por meio da análise do ensino da matemática, mas interpretamos ser aplicável para qualquer área do conhecimento, pois as principais preocupações do autor é a aprendizagem do aluno. Para o autor, a construção do conhecimento tem como base as experiências e percepções e, consequentemente, filia-se ao construtivismo.

[...] construtivismo deriva de uma posição filosófica [...] construímos nosso conhecimento do nosso mundo a partir de nossas percepções e experiências, que são mediadas por nosso conhecimento prévio. A aprendizagem é o processo pelo qual os seres humanos se adaptam ao seu mundo experiencial. (Simon, 1995, p. 2, tradução nossa) ${ }^{1}$

No âmbito nacional, encontramos Rossetto (2016, p.22), que se embasa em Simon (1995), e afirma que o destaque está na preocupação com a inter-relação entre os conhecimentos do professor, seu pensamento, reflexões, atitudes que introduzem a THA no ensino. Para a autora, a THA é uma alternativa ao professor para entender a construção dos objetivos de aprendizagem,

${ }^{1}$ Constructivism derives from a philosophical position [...] we construct our knowledge of our world from our perceptions and experiences, which are themselves mediated through our previous knowledge. Learning is the process by which human beings adapt to their experiential world. 
das tarefas e hipotetizar a maneira como os alunos poderiam lidar com o conteúdo em sala de aula. Ela apresenta três ações: o planejamento, a execução do planejamento e o replanejamento.

Então, para auxiliar na (re)construção do conhecimento geográfico, a THA associada a quarta sequência didática, teve a intenção de obter clareza e direcionamento na construção de nossa proposta de ensino da Geografia inspirada no jogo do RPG.

O RPG foi considerado um jogo de mesa evoluído, que teve uma interpretação física de histórias narrativas em formato de jogo. Schmit (2008, p.37) aponta que, no Brasil, surgiu em 1991, o primeiro RPG produzido no país - Tagmar, com cenas da nossa paisagem, Desafio dos Bandeirantes, que foi formulado com mitos e lendas da história da época dos bandeirantes.

O RPG é definido como sendo uma contação de história:

[...] interativa, quantificada, episódica e participatória, com uma quantificação dos atributos, habilidades e características das personagens [...]. Além disso a história é definida pelo resultado das ações das personagens e as personagens dos jogadores são as protagonistas. (Schmit, 2008, p. 47).

Por desenvolver a imaginação, consideramos que trabalhar conceitos geográficos em aventuras fictícias poderia ser uma alternativa do professor instigar mais nos alunos o gosto pela Geografia Física.

Amaral (2013, p.10) realizou uma pesquisa utilizando o jogo do RPG em aulas de Física e considerou que o RPG é:

[...] uma brincadeira vivenciada essencialmente pela fala. Cada jogador vai exprimindo oralmente as ações de seus personagens à medida que o Mestre vai colocando os desafios [...].

Na educação, o RPG pode ser incorporado, como fez Amaral (2013, p.13-14), de maneira interdisciplinar, contextualizado e cooperativo, com o propósito de motivar e melhorar as relações sociais entre os alunos e professor e entre aluno e aluno. O mesmo autor ressalta que o RPG possui regras como: criação personagens; relação de habilidades, nível de habilidade; riqueza do personagem, equipamento de campanha, testes do jogo, combates e a ficha de personagem; que foi adaptado em sua pesquisa.

Como forma de obter um feedback, Amaral (2013) solicitou aos alunos um texto descritivo-dissertativo relatando, prazerosamente, seus sentimentos e o que aprendeu no jogo, partindo dessas leituras, considerou positivo, pois os alunos conseguiram interagir, discutir e buscar soluções para os erros, elaborando conclusões; percebendo assim que, "ter a satisfação do educando é motivador" (Amaral, 2013, p. 17).

Então, partindo dos estudos de Zabala (1998), Simon (1995), Rossetto (2016), e Amaral (2013), elaboramos a Trilha na Floresta, cuja proposta está associada aos conceitos geográficos: relevo, vegetação e clima com o uso da tecnologia digital. No seu desenvolvimento, foi considerado o aluno como membro ativo e participativo junto com o professor.

\section{Resultados e Discussão}

Analisaremos, na continuidade, as falas hipotéticas elaboradas em uma Trilha na Floresta, com alunos do $6^{\circ}$ ano do ensino fundamental. Nela apresentaremos a articulação realizada entre os estudos de Zabala (1998), sobre Sequência Didática; Amaral (2008), sobre os Jogos RPG; e Rossetto (2016) e Simon (1995), sobre a THA.

Os diálogos hipotéticos ocorrem no contexto das narrativas produzidas a partir da história Trilha na Floresta, introduzida com base nas orientações sobre o trabalho de campo, pois, no desenvolvimento de uma atividade, é necessário criar condições que gerem motivação - a alma de uma Sequência Didática (Zabala, 1998), visto que os alunos precisam da orientação e motivação do professor para que olhem a atividade com curiosidade e desejo em participar.

O jogo inicia-se com o mestre (professor) ao ler a introdução da história para os participantes, que interpretarão seus personagens durante o desenrolar da trama. Cada uma das personagens pode ser composta por um aluno, bem como um grupo 
de alunos. Diferente dos jogos tradicionais que, conforme a história se concretiza e é atribuído aos participantes uma série de pontuação, optou-se por atribuir somente um ponto ao participante, ou grupo, que apresentar de forma coerente o conceito da geografia mobilizado pelo mestre no desenrolar da história.

Buscando motivar os alunos em relação a construir uma história, bem como incitando-os ao desenvolvimento da criatividade, foi elaborado no aplicativo Apresentação, da Google, uma apresentação de slides com imagens de paisagens a serem observadas pelos alunos quando imaginam o passeio pela floresta.

Cabe destacar que nessa atividade os alunos são livres para imaginar e, junto ao mestre, podem mobilizar uma série de conhecimentos e rememorar situações que viveram. Todavia, o mestre tem a função de realinhar o jogo a todo momento que o grupo se afastar do objetivo de aprendizagem, a apresentação de slide projetada no celular de cada aluno, bem como na televisão, em sala de aula, pode contribuir para a efetivação desse resgate.

Para este artigo, analisaremos a introdução do aluno no jogo e a abordagem dos conteúdos: Araucária, Pontos Cardeais e Depressão. Todavia, em Lima (2019), pode-se encontrar o plano de aula detalhado do jogo, bem como toda a Trajetória Hipotética elaborada para a Trilha da Floresta. Além desses conteúdos, o jogo contemplou: lago, nascente, margem, planície e morro.

O início da Trilha na Floresta tem como introdução as orientações prévias para seu desenvolvimento, ou seja, do trabalho de campo. Também foi apresentado aos alunos um mapa via o aplicativo Apresentação do Google, com intuito de promover o interesse e engajamento do aluno no jogo.

Para a saída, os alunos foram orientados anteriormente que levassem uma mochila com garrafa de água, comida, bússola e outros itens livres, usassem roupa confortável de caminhada, boné e tênis. A professora levava também uma bússola, garrafa de água, comida, canivete, mapa da área e vestia roupa confortável de caminhada (Lima, 2019, p.56).

Figura 1 - Slide de Instruções do Jogo.

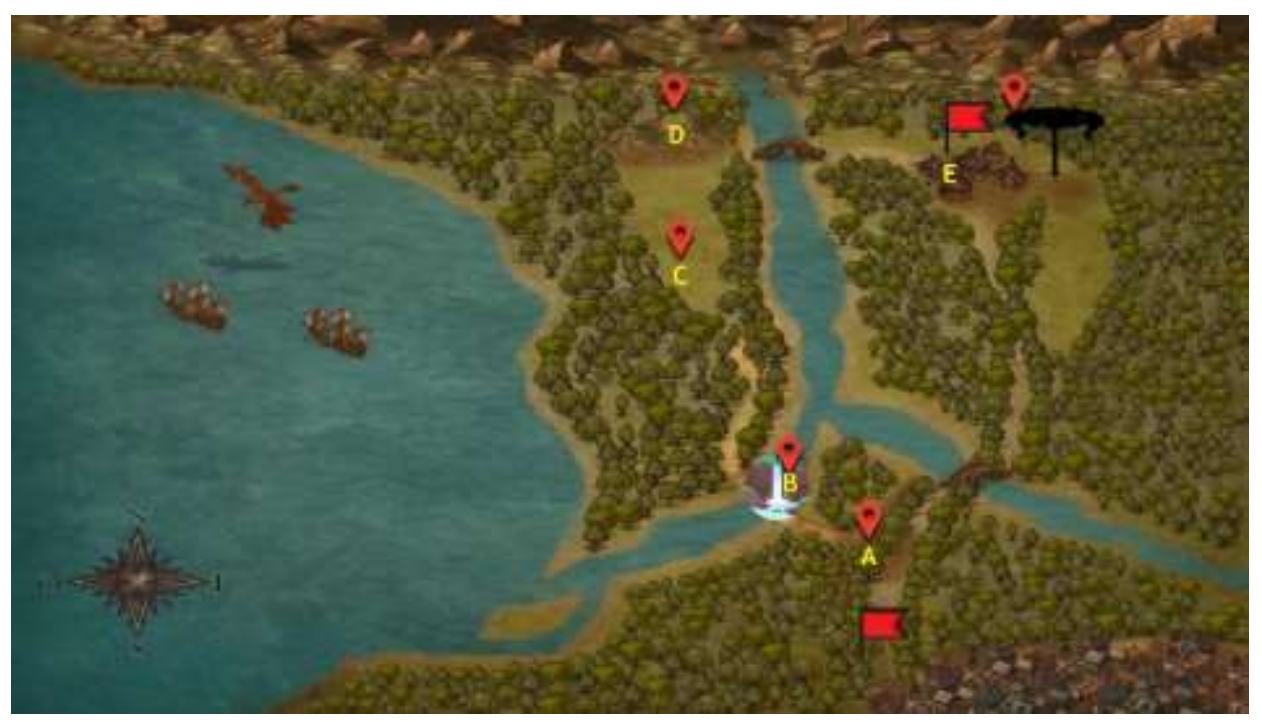

Fonte: Lima (2019, p.61).

As regras estabelecidas no diálogo tendem a gerar nos alunos o senso de cooperação em equipe e avaliação de suas atitudes. Amaral (2008, p.63) argumenta que a apresentação das regras e a liberdade dos alunos escolherem sua personagem pode gerar maior interesse na participação. Dessa forma, no trecho seguinte, destaca-se o mestre reiterando os objetivos da atividade, com o intuito de esclarecer aos alunos o contexto em que o RPG se dará e os limitantes da atuação de cada um no jogo. 
M: Somos exploradores e vocês terão que usar a imaginação durante toda narração acompanhando as orientações, ok! Nossa visita em campo será em uma floresta, cujo ponto de encontro é uma Araucária (Lima, 2019, p.60).

A participação dos alunos e seus personagens se dá na sequência, após o mestre ter delineado o contexto em que a história se constitui. Possibilitar ao aluno expor sua imaginação, sua forma de compreender o mundo, configura um ambiente que proporciona que ele apresente seus conhecimentos prévios, o ponto de partida para a problematização dos conteúdos (ZABALA 1998). Por outro lado, o professor, de acordo com Amaral (2008), conhece as dificuldades da sua turma de alunos, de modo a levar esses elementos para debate e esclarecimentos, possibilitando condições de superação.

O mestre abre espaço a participação dos PJ:

M: Quem conhece ou já viu uma Araucária?

PJ1: Eu já vi indo para Curitiba.

PJ2: No sítio de meu avô tem umas 3, mestre.

M: Alguém mais conhece?

Já viu em foto, imagem, ou em reportagem na tv? (Lima, 2019, p.61).

Ao longo da atividade, fez-se necessário acrescentar o papel do narrador, que pode ser ocupado por um aluno ou uma dupla. Ele tem a função de instigar a imaginação dos demais, a partir de sua interpretação mediante sua entonação de voz. Amaral (2008, p.162) considera que podemos comparar a experiência dos alunos ao diálogo do narrador, com o objetivo de envolver os alunos dispersos em diálogos que acontecerão nas próximas falas. Na sequência, é apresentado um exemplo da atuação do narrador.

Narrador: Há um momento de silêncio entre todos que fazem uma fisionomia de pensamento, mas não se manifestam. (Lima, 2019, p. 61).

Zabala (1998) correlaciona a aprendizagem dos alunos às perguntas que são realizadas, problematizadas e respondidas em sala de aula, o que denota que o mestre, durante o jogo, ocupa o papel de problematizador do enredo. Dessa forma, é nas simulações que envolve a conversa entre o Mestre e os jogadores que se vislumbra a aprendizagem, ou seja, são nessas ações interativas que o mestre pode avaliar as afirmações dos jogadores e reconduzi-los no processo de problematização do contexto construído.

Interpretamos, também, uma oportunidade de que se estabeleça um processo de avaliação dos conhecimentos prévios, da expressão livre do aluno em participar, bem como a construção do conhecimento científico, principalmente quando são conduzidos pelo mestre no enredo do jogo. Rossetto (2016, p.26) afirma que a avaliação da aprendizagem pode se configurar, também, um momento em que o professor pode refletir sobre a sua prática, ou seja, o professor pode se valer das informações advindas da avaliação para ajustar seu planejamento, bem como todo o processo que envolve a THA.

Consequentemente, o processo interativo no jogo, além de ser uma oportunidade de aprendizagem para o aluno, pode se configurar um momento no qual o professor pode refletir sobre a sua prática, procurando cada vez mais se aproximar das demandas advindas da realidade em que atua. Em suma, segundo Amaral (2008), o RPG, ao ser utilizado em uma perspectiva pedagógica, possibilita uma modificação das relações sociais estabelecidas em sala de aula.

No diálogo sequente, pode-se observar o Mestre em tentativas de aprofundamento do conteúdo, levando os alunos a relatarem características da Araucária. Interpretamos uma possibilidade de intensificar as relações interativas estabelecidas durante o jogo.

M: Muito bom, quem já viu uma Araucária, sabe de onde ela é típica, natural? 
PJ4: Mestre, eu li em uma revista, que ela nasce em lugares mais frios, não gostam de calor, é isso mesmo?

PJ5: Eu também assisti numa reportagem sobre isso Mestre.

M: Que bom que vocês estão se recordando, isso mesmo, ela é típica de clima mais frio, de locais mais elevados do planalto. (imagens de araucária) (Lima, 2019, p.61).

Nesta investigação, as TDIC foram utilizadas por meio de uma apresentação de imagens que pode ser visualizada nos celulares dos alunos, bem como na TV ou DATASOW. As imagens escolhidas, junto às definições dos conceitos geográficos, possibilitam ao aluno associar o conceito ao objeto no contexto do jogo, fomentando e direcionando a imaginação de acordo com os objetivos de aprendizagem. A imagem elucida os diversos momentos no jogo em que o clique no slide e as imagens são acionados pelo mestre.

M: Então no celular cliquem no $\boldsymbol{E}$ pertinho da bandeira vermelha. Acharam?

Cliquem no $E$

Figura 1 - Araucárias no município de Campos Novos - SC (Lima, 2019, p.61).

Figura 2 - Fragmentos da Apresentação de Slide Conteúdo Araucária.

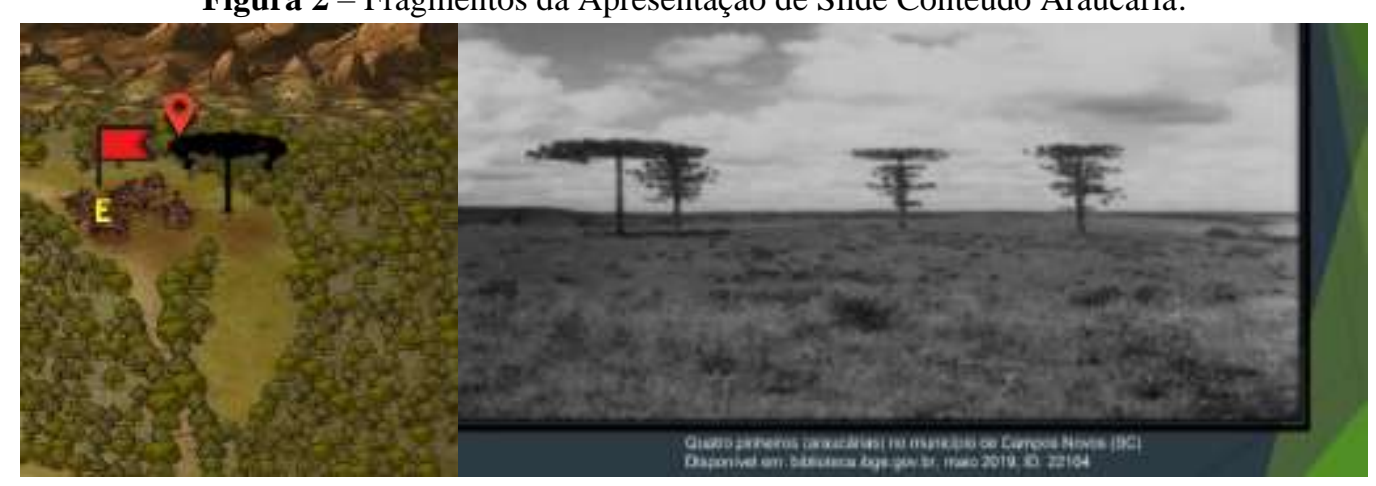

Fonte: Lima (2019, p.62).

Com o objetivo de aprofundar o conteúdo abordado e resgatar da memória dos alunos suas lembranças e experiencias que há tiveram com a temática em estudo, o Mestre (professor) continua o diálogo, explorando outras características da Araucária, como o seu fruto, o pinhão. Interpretamos que essas tentativas visam aproximar o aluno da temática, pois o pinhão é um alimento tradicional em algumas localidades no Brasil. Todavia, o professor deve procurar ser sensível ao cotidiano dos alunos e utilizar situações coerentes com essa realidade. Em suma, busca-se a explicitação de respostas intuitivas (Zabala, 1998).

M: O que aparece?

PJ3: Uma Araucária.

M: Quem já comeu o fruto da Araucária?

Qual é mesmo o nome deste fruto?

PJ6: Minha mãe sempre compra na rua, naqueles carrinhos sabe mestre, que fica na esquina no centro da cidade, aí ela cozinha, depois descasca e comemos puro ou ela mistura tipo no arroz.

M: Quem mais???

PJ7: Eu também como e é bem gostoso (Lima, 2019, p. 64).

No diálogo sequente, o mestre (professor) insere um novo conteúdo, no caso os pontos cardeais, para que os jogadores pudessem se localizar no jogo. Levando em consideração que "os estudantes também fazem perguntas, e o professor [...] encaminha a THA a partir das possíveis dúvidas" (Rossetto, 2016, p. 58). Tomamos o cuidado de mobilizar conhecimentos sobre como os alunos lidariam no jogo e, consequentemente, as possíveis dúvidas e esclarecimentos que poderiam emergir no processo. 
M: Ótimo, vamos continuar e acompanhem em silêncio, e sigam as instruções, ok?

Sabemos que a direção a ser seguida é o Norte e como referência uma árvore de porte alto, o pinheiro (Araucária) como já vimos, guardem a imagem na memória.

Lembram como é uma bússola?

Para que serve?

PJ8: Eu nunca vi uma.

M: Sério, e como você imagina o seu formato?

PJ8: Quadrada?

M: Quem mais não conhece?

PJ1: Eu tenho uma que ganhei de presente de meu pai quando fomos fazer trilha mestre.

M: Que legal, e diga como ela é, você se lembra?

Pj1: Sim, Deixe ver: redonda, com números, um ponteiro de dois lados que aponta sempre ao Norte.

PJ9: Sabichão, kkkkkkk (Lima, 2019, p.65).

Devemos também considerar os imprevistos e momentos de conflitos entre os jogadores. Nesse caso, é pertinente que o professor abra em seu planejamento espaço para pensar em reformulações. Essas dificuldades podem estar atreladas às condutas dos alunos, bem como no uso das TDIC no contexto do jogo, mostrando que o professor deve estar pronto a resolver ou conduzir a uma solução. Interpreta-se, também, que se tem configurado um contexto em que os jogadores e professores podem aprender com seus erros (Amaral, 2008).

\footnotetext{
M: Então vamos ver a rosa dos ventos ao Oeste do mapa no celular.

Cliquem no $\boldsymbol{A l}$ novamente

M: Clicaram?

Estão vendo? Sim, pera aí mestre, o meu travou.

PJ5: Me dá aqui PJ10 (pegou da mão dela), eu arrumo.

PJ10: Seu bruto, me devolve.

M: Calma gente, ele só vai arrumar e devolve.

PJ5: Aqui está, arrumado (mandou uma piscadinha a ela).

M: Vamos continuar (Lima, 2019, p. 65).
}

Ao propor o jogo, faz-se necessário estruturar momentos de regresso em relação à abordagem do conteúdo, de modo que se possa avaliar a compreensão por parte dos jogadores. Dessa forma, estamos preocupados que o jogo contribua para que os alunos possam sintetizar o conteúdo, elaborar generalizações e conclusões.

M: Voltem para Rosa dos Ventos (RV).

Observem: o Norte e Sul, e o que mais tem escrito?

Pjc11: Leste onde nasce o sol e Oeste o pôr do sol.

M: Muito bem, vão esquecer? Espero que não, é bem simples, ok! (Lima, 2019, p.66).

$\mathrm{Na}$ sequência, pode-se observar nas hipóteses um momento em que um acidente gerou um contexto no qual o mestre (professor) pode introduzir o conceito de depressão. Nesse caso, a queda foi introduzida, de modo que cada um dos personagens pudesse imaginar a maneira como caíram e procurar justificar o porquê da queda. Esse foi o ponto no qual o conteúdo foi inserido.

PJ3: Ai, hum, ah, socorro, que dor.

Onde caímos, pergunta uma PJc11?

M: Vocês caíram em uma depressão.

PJ3: Que rolada demos $k k k k k k k k$.

M: Lembram da figura da depressão gente??

PJ12: Eu lembro que é tipo um buraco.

PJ13: Você não sabe explicar direito né, não presta atenção na aula e depois fica falando coisa errada. 
M: Calma pessoal, não vamos falar dessa forma com a PJ.

PJ13: Foi mal mestre, desculpe.

M: Quem mais lembra?

PJ14: É uma forma de terreno mais baixo que o terreno ao redor.

M: Ele está certo pessoal?

M: Lembram agora vendo a figura?

PJ3: Tem mais imagem? (Lima, 2019, p.67).

Figura 3 - Fragmentos da Apresentação de Slide Conteúdo Depressão.
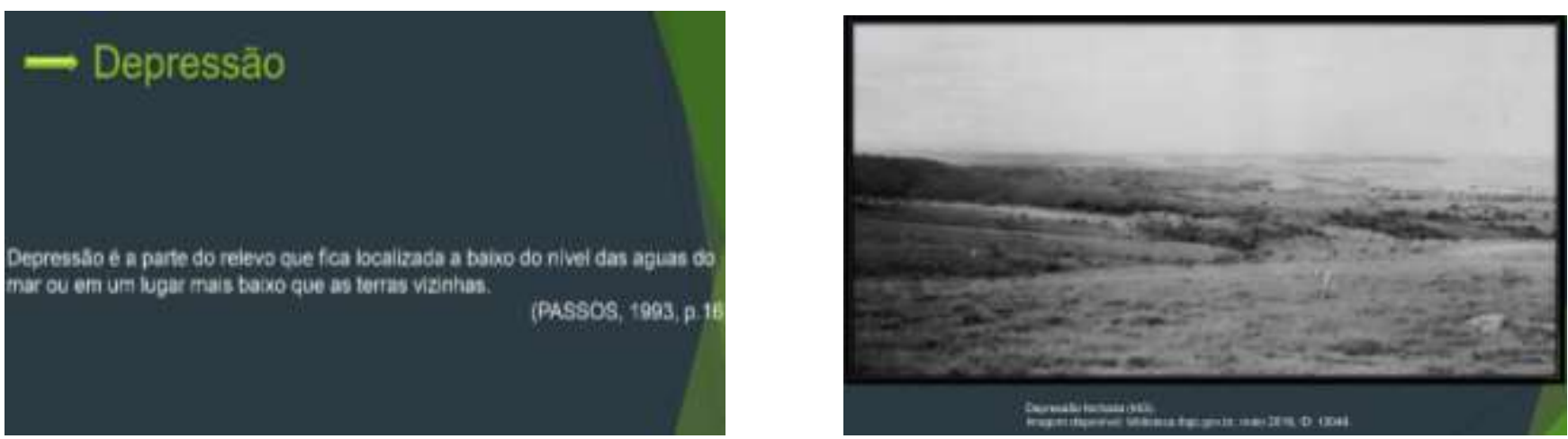

Fonte: Lima (2019, p.67).

No planejamento do jogo, o professor precisa imaginar todas as possíveis variáveis que podem interferir no processo de ensino e aprendizagem do conteúdo, para que possa explicar e rever com os alunos naquele momento em que ocorreu o fato. Estar preparado é o ponto chave para atingir o objetivo traçado, mas como os alunos são imprevisíveis, e o conteúdo vasto, o professor precisa rever da melhor forma de conduzir e reconduzir os alunos durante o jogo. Amaral (2008, p.162) considera que os jogos RPG com uma ou mais disciplinas é um "recurso para sistematização e contextualização de conceitos científicos, desde que permita, ao estudante, experimentar esses conceitos em situações práticas, bem próximas daquelas que encontram no seu cotidiano". Foi fundamentado nessa afirmação que a proposta de ensino aqui comunicada foi realizada.

Finalizando a análise Trilha na Floresta, destacamos que a presença dos diferentes slides e figuras no decorrer da dinâmica, teve o propósito intencional de instigar a curiosidade do aluno, motivar a sua imaginação, avaliar o conteúdo aprendido ou não por ele e readequar, se necessário. Zabala (1998, p.72) destaca que o diálogo constante do professor com os alunos é importante para que não se perca a motivação, o interesse em continuar a dinâmica. A curiosidade do aluno ao ver mais imagens, remete ao professor um feedback do interesse, da atenção do aluno, fato importante no processo de aprendizagem e que, no contexto do jogo, é fomento pelo uso das TDIC.

\section{Considerações Finais}

Diante das análises realizadas, compreendemos que o ensino da geografia visa, dentre outros aspectos, contribuir com a aprendizagem dos acontecimentos do meio ambiente. Usar a tecnologia para trazer virtualmente simulações do mundo real associadas à Trajetória Hipotética de Aprendizagem, sequência didática e inspirações no jogo RPG, gerou um importante caminho de nova forma de desenvolver o ensino, contribuindo com os processos de ensino e da aprendizagem da Geografia Física.

As análises apresentadas no presente artigo, revelaram que o professor terá no RPG pedagógico, da forma como desenvolvemos, mais uma possibilidade de desenvolver a sua criatividade e a formulação de outras experiências em sala de aula, proporcionando, aos estudantes, atividades diferenciadas que podem favorecer o estudo e compreensão de conceitos da Geografia Física em situações que simulam a realidade. 
Dessa forma, a articulação teórica realizada entre as Sequências Didáticas, a Trajetória Hipotética de Aprendizagem e o RPG se configuram um ambiente de aprendizagem para qualquer conteúdo da disciplina geografia, de modo que basta ao professor e alunos imaginarem um enredo que pode se passar na própria localidade, independente de residirem na zona urbana ou rural, bem como outras partes do mundo, em um movimento de simulação de uma viagem. Em suma, basta imaginação, curiosidade e um rico enredo para vislumbrarmos a aprendizagem.

\section{Agradecimentos}

A Coordenação de Aperfeiçoamento de Pessoal de Nível Superior - Brasil (CAPES) - Código de Financiamento 001. A Fundação Nacional de Desenvolvimento do Ensino Superior Particular.

\section{Referências}

Amaral, R. R. (2008). Uso do RPG Pedagógico para o Ensino de Física. (Dissertação de mestrado). Universidade Federal Rural de Pernambuco.

Amaral, R. R. (2013). RPG na escola: aventuras pedagógicas. UFPE.

Brasil (2012). Conselho Nacional de Educação. Conselho Pleno. Res. № 2, de 30 de janeiro de 2012, que define as Diretrizes Curriculares Nacionais para o Ensino Médio. Diário Oficial da União, Poder Executivo.

Compiani, M. A. (1991). A relevância das atividades de campo no ensino de Geologia na formação de professores de Ciências. Cadernos IG/UNICAMP, 1(2), $2-25$.

Lima, S. P. (2019). Uma proposta para o ensino de geografia física inspirada nos jogos RPG. (Dissertação de mestrado). Universidade Pitágoras Unopar, Londrina.

Martineau, S., Simard, D., \& Gauthier, C. (2001). Recherches théoriques et spéculatives: considérations méthodologiques et épistémologiques. Recherches Qualitatives, 22, 3-32.

Nascimento, M. S. (2020). Conceptions about geotechnologies as a didactic resource for teaching Geography. Research, Society and Development, 9(3), e124932671.

Organização das Nações Unidas para a Educação, Ciência e a Cultura. (2015). Tecnologias para a transformação da educação: experiências bem sucedidas e expectativas. Autor.

Organização das Nações Unidas para a Educação, Ciência e a Cultura. (2016). Transformando nosso mundo: a agenda de 2030 para o desenvolvimento sustentável. Educação 2030. Autor.

Pedrochi-Junior, O. (2018). A avaliação formativa como oportunidade de aprendizagem: fio condutor da prática pedagógica escolar. (Tese de doutorado). Universidade Estadual de Londrina.

Rossetto, H. H. P. (2016). Trajetória Hipotética de Aprendizagem sob um olhar realístico. (Dissertação de mestrado). Universidade Estadual de Londrina.

Rossetto, H. H. P. (2021). O desenvolvimento de um framework de trajetórias de ensino e aprendizagem de matemática (Tese de doutorado). Universidade Estadual de Londrina.

Rocha, M. A. (2018). Professores de Geografia e o Conhecimento Tecnológico do Conteúdo. Colóquio Internacional de Educação Geográfica. Seminário Ensinar Geografia na Contemporaneidade.1, 4.

Sachs, L., Bailão, T. M., \& Fogaça Carvalho, D. (2021). Problematizações sobre a delimitação entre rural e urbano e suas implicações na educação. Revista Brasileira De Educação Do Campo, 6, e10709. https://doi.org/10.20873/uft.rbec.e10709

Simon, M. A. (1995). Reconstructing Mathematics Pedagogy from a Constructivist Perspectivel. Journal for Research in Mathematics Education, 26 (2), 114145.

Schmit, W. L. (2008). RPG e Educação: alguns apontamentos teóricos. (Dissertação de Mestrado). Universidade Estadual de Londrina.

Toledo, M. C. M., Takayama, C. H. \& Bourotte, C. L. M. (2014). Intemperismo simulado em animação gráfica. Terra e Didática. 10 (3), $351-356$.

Van Der Maren, J. M. (1996). Méthodes de recherche pour l'éducation. Bruxelles: De Boeck and Larcier.

Zabala, A. (1998). A Prática Educativa: como ensinar. ArtMed. Amaral, R. R. (2008). Uso do RPG Pedagógico para o Ensino de Física. (Dissertação de mestrado). Universidade Federal Rural de Pernambuco. 